Anuario Latinoamericano

Ciencias Políticas

y Relaciones Internacionales

vol. 4, 2017

pp. 255-272

DOI: 10.17951/al.2017.4.255

\section{Impunity and transitional justice in the recent history of Guatemala: towards a democratic rule of law} hacia un Estado democrático de derecho

\author{
María Patricia González Chávez ${ }^{1}$ \\ UNIVERSIDAD AUTÓNOMA DE MÉXICO, \\ CIUDAD DE MÉXICO, MÉXICO \\ $\triangle$ patygonzalezchavez@gmail.com
}

\title{
RESUMEN
}

En la lucha actual contra la impunidad en Guatemala, desde el Ministerio Público y la Comisión Internacional contra la Impunidad en Guatemala (CICIG), con el soporte de la Organización de las Naciones Unidas (ONU) y la Comunidad Internacional, se han procesado responsables de delitos de lesa humanidad durante el conflicto armado interno (1960-1996). El caso del Comando Regional de Entrenamiento de Operaciones de Mantenimiento de la Paz (CREOMPAZ) por el que están procesados 11 militares es paradigmático: confluyen en el mismo sitio, el resguardo de la ONU y lo que fue la Zona Militar No. 21, y el hallazgo de 533 osamentas de víctimas de la represión de fuerzas de seguridad del Estado en los 80. Esto revela una situación compleja: un gobierno recién entrante con vinculación a los militares procesados y la resistencia a un Estado de derecho democrático desde las tradicionales fuerzas del poder.

PALABRAS CLAVE: Guatemala, historia reciente, impunidad, justicia transicional.

\section{ABSTRACT}

In the current actions against the impunity in Guatemala, the Public Prosecutor Office and the International Commission against Impunity in Guatemala (ICIG), with the support of the United Nations (UN) and the International Community,

\footnotetext{
1 Licenciada en historia por la Universidad de Guadalajara y Maestra en Derechos Humanos y Democracia por FLACSO-México. Doctoranda del Programa en Estudios Latinoamericanos de la Universidad Nacional Autónoma de México. Desarrollo profesional internacional en contextos de conflicto y construcción de la paz. Temas de especialización para formación, investigación y publicaciones: gobernabilidad democrática, reforma del sector seguridad, seguridad ciudadana, justicia transicional, memoria histórica y violencia.
} 
prosecutes those responsible for human rights violations during the internal armed conflict (1960-1996). The case of Comando Regional de Entrenamiento de Operaciones de Mantenimiento de la Paz (CREOMPAZ), in which 11 military officers were judged, is paradigmatic: in the same site converged the UN shelter, the Military Zone No. 21 and the finding of skeletal remains of 533 victims of repressions of the security forces in the 1980s. This reveals the complex situation: an incoming government with ties to the prosecuted military officers and the resistance against a democratic rule of law from the traditional powers.

KEYWORDS: Guatemala, recent history, impunity, transitional justice.

\section{Introducción}

\section{Reflexiones previas}

La impresión emotiva y racional en ese preciso momento en que tenemos en nuestras manos un asunto del pasado, pero que es tan vívidamente presente, requiere cruzar varios horizontes de pensamiento, imaginación y, sobre todo, de racionalidad. Las narrativas que rodean nuestra imaginación al cruzar los temas que trataremos se movilizan en diferentes tiempos y consonancias apurando una forma de reaccionar que pueda dar cuenta de un sentimiento difícil, que se debate entre la incertidumbre de creer o la certidumbre de saber hasta dónde puede llegar el ser humano.

El asunto que presentamos convoca fuertemente a la sensación anterior, y se refiere al tema de aportar en la construcción de una narrativa de la historia reciente desde ángulos complejos que nos llaman poderosamente a ser cautos en la intención y en la investigación, porque de eso depende una percepción, un aprendizaje y una actitud que nos incluye de una u otra manera, en estos saberes que son de todos, aunque no todos lo sepan. Es decir, que elegimos una opción para explorar y textualizar un conocimiento que se convierta en una contribución para analizar y construir, pero sobre todo a fortalecer la sensación del otro y lo que eso nos implica en nuestro universo discursivo.

\section{Antecedentes y geodiacronía del tema}

Nos ubicamos en la Centroamérica de la segunda mitad del siglo veinte, en el contexto de una difícil confrontación de todos los órdenes de la vida en sociedad, que se han nombrado como conflictos nacionales, en El Salvador, Guatemala y Nicaragua. Honduras, con problemas estructurales similares a los otros países, queda atrapado en la conflictividad de la región. Los alcances, naturaleza y dimensiones de cada uno son distintos, aunque conservan realidades muy similares; así también sucede con sus temporalidades, ya que 
aunque podemos datarlos con especificidades, confluyen en un momento preciso en los Acuerdos de Paz de Esquípalas a mediados de la década de los $80 .^{2}$

Concretamente nos adentramos en la historia de Guatemala en un punto imaginario de intersección entre el presente y los hechos sucedidos en la década de los ochenta, justo en el llamado conflicto armado interno, para abordar el tema de violaciones masivas a los derechos humanos que hoy salen a luz en el marco de procesos de memoria, justicia y reparación que se impulsan en este país de unos años para acá.

El conflicto armado interno en Guatemala se ubica de 1960 a 1996 y se describe como un enfrentamiento producto del levantamiento de movimientos guerrilleros de izquierda contra el régimen autoritario y militar. Sin embargo, esa tipificación de "enfrentamiento" ha distorsionado la realidad de lo sucedido, en una estrategia de desplazamiento de información y análisis en las narrativas históricas oficiales, que se han esforzado, ya cada vez con muchas menos posibilidades, de minimizar la desbordada reacción del Estado para combatir los movimientos guerrilleros, utilizando esta justificación para implementar una de las más devastadoras, violentas y crueles estrategias de contrainsurgencia en la segunda mitad del siglo XX en el mundo.

Como legado de la contrainsurgencia, se contabilizan miles de víctimas y sobrevivientes como resultado de masivas violaciones a los derechos humanos, que se establecieron en más de 250.000 entre muertos y desaparecidos. Esto quedó registrado en las dos Comisiones de la Verdad: Informe "Guatemala: Nunca Más", del Proyecto Interdiocesano "Recuperación de la Memoria Histórica" (REMHI) en 1998; ${ }^{3}$ y el Informe "Memoria del Silencio" de la Comisión del Esclarecimiento Histórico (CEH) de las Naciones Unidas, de 1999. En 1996, con la firma de los Acuerdos de Paz en México el 29 de diciembre, entre el Gobierno de la República de Guatemala y la Unidad Revolucionaria Nacional Guatemalteca (URNG), se pone fin al conflicto. “... la Comisión para el Esclarecimiento Histórico (CEH) registró un total de 42.275 víctimas, incluyendo hombres, mujeres y niños. De ellas, 23.671 corresponden a víctimas de ejecuciones arbitrarias y 6.159 a víctimas de desaparición forzada. De las víctimas plenamente identificadas, el $83 \%$ eran mayas y el $17 \%$ eran ladinos. Combinando estos datos con otros estudios realizados sobre la violencia política en Guatemala, la CEH estima que el saldo en muertos y desaparecidos del enfrentamiento fratricida llegó a más de doscientas mil personas" (CEH 1999: 21).

2 Entre 1986 y 1987, el presidente de Guatemala promovió el "Proceso de Esquipulas" que tenía como fin lograr la "Paz firme y duradera" para la región. El Acuerdo fue firmado en la ciudad de Guatemala por los cinco presidentes centroamericanos el 7 de agosto de 1987: de Guatemala, Vinicio Cerezo; de El Salvador, José Napoleón Duarte; de Nicaragua, Daniel Ortega; de Honduras, José Azcona Hoyo; y de Costa Rica, Óscar Arias Sánchez.

3 El asesinato de Monseñor Juan José Gerardi Conedera a dos días de haber presentado el REMHI, en el centro de la ciudad, da cuenta del clima que se vivía y del rechazo a las acciones que empezaban a desentrañar las violaciones a los derechos humanos durante el conflicto.
La impunidad y la justicia transicional en la historia reciente de Guatemala: hacia un Estado democrático de derecho

María Patricia González Chávez 
La lógica del tiempo narrado era la Guerra Fría, esa forma dicotómica de comprender y resolver en los imaginarios y en la práctica las luchas por el cambio social que alcanzó una dimensión global y permeó desde las economías y filosofías hasta la cultura cotidiana de la época, y aún hoy tiene enorme presencia en ciertos contextos.

Pilar Calveiro hace un aporte reflexivo de enorme relevancia, que nos introduce en el pensamiento de la época cuando explica que "La organización bipolar de la Guerra Fría se basaba en una constelación de espacios y valores que reivindicaban lo estatal, lo público y lo político como posibles principios de universalidad. Admitía la lucha, la confrontación y la revolución, como formas, si no únicas, válidas y valiosas de la política. Se definían y guardaban las fronteras -nacionales, ideológicas, de género-. Existía una extraordinaria tendencia a realizar clasificaciones y, sobre todo, formas de organización binarias -explotados y explotadores, justo e injusto, correcto e incorrecto-. Las personas reivindicaban la disciplina, la razón, el esfuerzo -que las instituciones grababan en ellas- como parte de sus logros. Por supuesto, estos rasgos convivían con sus contrarios y con toda la gama de matices que jamás se pueden expulsar de la realidad, pero se podría decir que, tendencialmente, organizaban la visión del mundo" (Calveiro 2005: 10).

Para el caso guatemalteco, ubicado en esa dimensión temporal, es posible apreciar que al statu quo del país, le fue fácil adaptar dicha visión dicotómica externa al contexto local, para confrontar al movimiento guerrillero y alineado a las prácticas represivas de ese tiempo que dieron vida a la denominada Doctrina de Seguridad Nacional, con la cual las élites económicas y políticas convierten a los sistemas de seguridad de la época en sus aliados encargados de la estrategia para contener y prevenir en futuro cualquier acción de cambio que amenazara sus intereses concretos.

Y a la luz de los principios axiológicos y prácticos de dicho marco doctrinario, se operaron una de las más fuertes acciones contrainsurgentes de la segunda mitad de ese siglo en Latinoamérica. Para Guatemala se cuentan en cientos de miles a las víctimas y los sobrevivientes, que desde finalizado el conflicto han permanecido en la lucha y a la espera de un tiempo para el rescate de lo acontecido, que lucha contra el olvido de aquellas fuerzas responsables; para la reparación de los graves daños infligidos a las poblaciones; y para la justicia, luchando contra la impunidad pasada y presente.

\section{Acercamiento al tema}

De acuerdo a la página del Ministerio de Defensa de Guatemala, se indica que la creación de CREOMPAZ fue en 2006: "El 28 de Junio a través de la Orden General para Oficiales No. 4-2006, por medio del Acuerdo Gubernativo No. 278-2006 de fecha 01JUN2006, y publicado en el Diario de Centro América el día 16JUN2006, en su Artículo Tercero es creado el 'Comando 
Regional de Entrenamiento de Operaciones de Mantenimiento de Paz', con sede en Cobán, Alta Verapaz, siendo suprimido el Centro de Instrucción y Entrenamiento del Ejército, según el Artículo Cuarto del citado Acuerdo Gubernativo" (MINDEF-GUA 2006).

La paradoja de CREOMPAZ resulta en que su ubicación es el mismo sitio correspondiente a la Zona Militar No. 21 durante el conflicto y el lugar donde se habían realizado excavaciones desde 2012 en búsqueda de víctimas y desaparecidos de la represión militar en los años 80. La investigación forense permitió el hallazgo de restos de alrededor de 500 personas inhumadas clandestinamente en el lugar, en el marco de un proceso judicial que imputaba a los militares de alta en ese momento, de ser presuntamente responsables de los hechos y cuya captura fue ordenada por el juez competente.

Así, la indescriptible sensación del pasado irrumpiendo en el presente llegó al país, una mañana del 7 de enero del 2016 con los titulares noticiosos informando de la captura de importantes militares relacionados a los casos "CREOMPAZ" y "Molina Theissen", éste último en relación a la detención y desaparición forzada del menor de 14 años, Marco Antonio Molina Theissen, en 1981.

\section{Perspectiva. Des-linealidad de las duraciones y multidimensionalidad}

\section{Des-linealidad de las duraciones}

La perspectiva de abordaje al tema que presentamos es socialmente compleja por dos motivos. El primero se refiere al asunto de las temporalidades que se cruzan entre pasado y presente, una y otra vez, para comprender el sentido último de lo que se está tratando. El segundo, porque tiene elementos de diferentes dimensiones de un análisis concreto, que para este caso confluyen, se interrelacionan y complementan ámbitos históricos, jurídicos, políticos y globales.

La tradición de pensamiento historiográfico de los Annales tuvo entre sus grandes aportes la forma de interpretar las duraciones de los procesos históricos, que define con claridad Aguirre al explicar que una de las tres claves braudelianas es la "atención permanente y la explicitación recurrente de las arquitecturas de la larga duración y del conjunto de las diferentes temporalidades o duraciones sociales, lo que construye una nueva mirada posible de todo el conjunto de los hechos sociales e históricos considerados" (Aguirre 1996: 62).

Esta concepción de las temporalidades nos es sumamente útil para explicar que, si bien el asunto de CREOMPAZ se destapa en el momento presente, nos remite en una trayectoria de larga duración hacia los años 80 de cuanto todo esto sucedió. Las etapas discontinuas de los procesos del pasado que se retoman como un momento vivo empiezan a tener significado al considerar que el tiempo crónico sucedió pero no el tiempo político ni el
La impunidad y la justicia transicional en la historia reciente de Guatemala: hacia un Estado democrático de derecho

María Patricia González Chávez 
jurídico, y ahí se entrelazan en una clara comprensión de linealidad para un análisis coherente y comprehensivo de los sucesos que se relatan y contextualizan en el presente.

Pero con esta herramienta teórica de las temporalidades podemos ir más allá en el análisis, y se refiere a la complejidad que significa una especie de des-linealidad en los procesos estudiados; marcando con más fuerza lo que no tiene una secuencia específica y nos interesa recuperar. Es una visión crítica desde la perspectiva de los sujetos; mientras que para el proceso político y jurídico hay procesos discontinuos por el tiempo que tuvo que pasar entre los sucesos y enfrentar a la justicia, para los sujetos involucrados desde las víctimas y los sobrevivientes, el tiempo ha sido sistemáticamente lineal, por las implicaciones físicas y emocionales, individuales y colectivas que han vivido. Es decir que tendríamos una comprensión de des-linealidades en las duraciones de los procesos vividos que nos llevan a una visión donde el presente y el pasado se deben comprender en paralelo.

En referencia al segundo aspecto de la perspectiva, la intrínseca conexión de cuatro dimensiones específicas, serían gráficamente claras si se consideraran una intersección imaginaria de cuatro ámbitos que confluyen en el tiempo actual y se convierten en los ángulos principales de observación, para construir un lienzo con cuatro cuadros principales: el análisis histórico de país, el análisis político de coyuntura, el proceso de la justicia y el análisis geopolítico global.

\section{Multidimensionalidad: un lienzo con formato a cuadros}

\section{Análisis histórico del país}

Tratar la historia política de las últimas décadas en Guatemala ha llevado ya mucho papel y tinta, desde diversas perspectivas y ámbitos de conocimiento, por lo cual sólo queremos aportar, con el fin de destacar su relevancia, que el proceso de transición debe ser considerado en dos dimensiones y que no siempre son convenientemente aclaradas con precisión, ya que dependen de distintos énfasis en la interpretación política. Por un lado, presenciamos un fuerte posicionamiento de la narrativa discursiva de la "transición a la democracia" y que hace referencia al proceso de instalación de la formalidad del paso a elecciones formales y surgimiento de gobiernos civiles, con un nuevo marco constitucional, en 1985. Por otro lado, una narrativa histórica de la "transición del conflicto a la paz", con la firma de los Acuerdos de Paz en 1996, dando el fin al conflicto armado interno.

Lo anterior no tendría mayor relevancia de no ser porque suceden en línea simultanea por un periodo significativo del tiempo, el avance del proceso democrático formal en el marco de campañas contrainsurgentes. Podríamos establecer de esta forma que existe una doble transición política; mutuamente diferenciada, pero que se entrelazan, con el mismo fin, "pacificar el país", pero 
con métodos distintos, formalidad civil-democrática y formas represivas de control bajo hegemonía militar. Todo como partes de un mismo plan, elaborado y ejecutado por los mismos actores.

En secuencia cronológica, los eventos más significativos desde la historia política reciente se representan en las siguientes dataciones.

De 1944 a 1954, un breve periodo democrático con los presidentes Juan José Arévalo Bermejo y Jacobo Árbenz Guzmán. En 1954, la intervención militar con apoyo norteamericano que coloca en la presidencia a Carlos Castillo Armas, y significa no sólo un regreso al autoritarismo militar, sino que se retrocede dramáticamente en cuanto a las reformas socioeconómicas modernizantes que se habían impulsado.

De 1960 a 1996, el Conflicto Armado Interno, que deja su legado de violencia e impunidad con crímenes de lesa humanidad de indescriptible crueldad y masividad a cargo de las fuerzas de seguridad del Estado autoritario; que hará pasar a la historia como un caso paradigmático de violencias internas extremas y de la capacidad destructiva de un régimen de poder que sustenta un sistema estructural de desigualdad y exclusión económica y social en todos los órdenes de la vida. "82. Las violaciones de los derechos humanos y hechos de violencia atribuibles a actos del Estado alcanzan el 93\% de los registrados por la CEH; dan cuenta de que las violaciones producidas por la represión estatal fueron reiteradas y que, aunque con diversas intensidades, se prolongaron en el tiempo de forma persistente, con especial gravedad del año 1978 al 1984, período en el cual se concentra el 91\% de las violaciones conocidas por la CEH. Actuando solos o en combinación con otra fuerza, en un $85 \%$ de todas las violaciones de los derechos humanos y hechos de violencia registrados por la $\mathrm{CEH}$, la violación es atribuida al Ejército y en un $18 \%$ a las Patrullas de Autodefensa Civil, organizadas por la misma institución armada" (CEH 1999: 42).

En 1984, se instala una Asamblea Nacional Constituyente que instala un proceso electoral democrático formal con el cual se celebran las elecciones que dan por triunfo al primer presidente civil en mucho tiempo, Marco Vinicio Cerezo Arévalo. Los secuencias de presidentes se suceden con dos momentos abruptos; en 1993 cuando es destituido Jorge Serrano Elías a mitad de su mandato; y la caída de Otto Pérez Molina, cuando renuncia el 2 de septiembre del 2015, a cuatro meses de finalizar su periodo, como resultado del proceso jurídico a que es sometido acusado de corrupción. El ahora expresidente Pérez Molina, general firmante de los Acuerdos de Paz, guarda prisión.

\section{Análisis político de coyuntura}

Para cubrir los cuatro meses del mandato inconcluso, se nombró un presidente interino, Alejandro Maldonado Aguirre, quien ya era vicepresidente desde el 14 de mayo del 2015, a raíz de la caída de la exvicepresidenta Roxana Baldetti, quien también guarda prisión actualmente procesada por casos de
La impunidad y la justicia transicional en la historia reciente de Guatemala: hacia un Estado democrático de derecho

María Patricia González Chávez 
corrupción. Maldonado ha estado siempre vinculado a los militares de posiciones más conservadoras.

Con este complejo escenario se realizan las elecciones en septiembre del 2015 bajo muchas presiones internas y externas, ${ }^{4}$ ganándolas el actual presidente Jimmy Morales, que proviene de la comedia y quien era conocido popularmente por tener un programa de televisión llamado "Moralejas", con cierto tipo de contenidos que han sido muy polémicos por los personajes satíricos que ha utilizado.

Sin embargo, lo que realmente tiene un fuerte impacto, es la estrecha relación de Morales con el sector más conservador de los militares que estuvieron relacionados con el conflicto armado interno. Lo anterior queda de manifiesto con el hecho de que su mentor y quien lo introdujo a las lides políticas para estas elecciones es el Teniente Coronel Retirado Edgar Justino Ovalle Maldonado. El caso de Ovalle es fundamental comprenderlo a luz de los procesos judiciales actuales, pues es un personaje que sirve de engranaje para la relación del pasado y del presente. Si bien puedan existir más casos, éste se encuentra ahora en la mira pública por su doble condición de alto impacto.

Por una parte, es fundador del partido que llevó a Jimmy Morales al poder, el Frente de Convergencia Nacional, integrado por militares que pertenecen a la Asociación de Veteranos Militares de Guatemala-AVEMILGUA, grupo de personas vinculadas a los sectores más duros y conservadores de las Fuerzas Armadas y con importantes señalamientos de violaciones a derechos humanos en el conflicto. Junto con Jimmy llega a colocarse también en una situación de poder al ser electo diputado por el mismo partido.

Por otra parte, es uno de los militares imputados en el caso CREOMPAZ, por un caso de desaparición forzada y delitos contra los deberes de la humanidad. Ante este hecho, el Ministerio Público solicitó un antejuicio contra Ovalle que no ha prosperado. Según documentos del conflicto desclasificados en los Estados Unidos de América (EE.UU.), este diputado fue oficial de operaciones de la Fuerza de Tarea Ixil de septiembre de 1981 a septiembre de 1982, periodo catalogado como uno de los más sangrientos vividos (Orozco 2016).

Lo anterior contribuye a incrementar la tensión política actual con la situación que se presenta en Legislativo, en donde las fuerzas de oposición han quedado con una importante representación en el Partido de la Unidad de la Esperanza, de centro-izquierda. El partido Frente de Convergencia Nacional de Morales no tiene base ni sectores políticos organizados significativos, por lo cual requería de más curules rápidamente para hacer contrapeso. La estrategia que se siguió fue la de conseguir sumar numerosos nuevos

4 La movilización del voto que dio el triunfo a Morales provino en una decisión de último momento en los sectores de poder en el país, contó con el apoyo de bases organizadas en las llamadas Patrullas de Autodefensa Civil (Ex PAC), que funcionaron como estructuras paramilitares en la estrategia contrainsurgente durante el conflicto. 
diputados "tránsfugas" en una rápida acción de cooptación, en el marco de las discusiones de una nueva Ley Electoral de Partidos Políticos que ha generado expectativa.

\section{El proceso de la justicia y la Comisión Internacional Contra la Impunidad en Guatemala-CICIG}

Del proceso de la justicia, resulta interesante constatar que hoy más que nunca se hace presente la sensación de que la impunidad tiene muchas caras, como si fuera un sólo objeto, pero observado desde distintos espacios y tiempos. Presenciamos una interesante lista de imputados relacionados con casos del pasado pero que actualmente se encuentran relacionadas con sectores de la impunidad del presente; diferentes tiempos cronológicos, pero las mismas caras y esencia: minar las condiciones mínimas de un Estado de derecho con principios democráticos.

Un elemento clave del análisis es ubicar el tiempo histórico de la creación de la CICIG como un punto de inflexión en el devenir del país, al colocarse el tema de la impunidad en un tema central de la agenda de país, como producto de la confluencia de intereses nacionales e internacionales en fortalecer el Estado de derecho democrático. La CICIG es un órgano independiente que tiene como misión el apoyo al sector justicia del país y trabaja desde un marco normativo bajo convenio de las Naciones Unidas y el gobierno de Guatemala, es un experimento único que los EE.UU. intenta replicar en otros países de la región.

El impulso de la CICIG a la justica es innegable, en sus distintas modalidades de intervención. Sin embargo es importante señalar que la contraparte nacional ha jugado un papel determinante, en la figura de las fiscales que se han sucedido; primero Claudia Paz y Paz que movilizó expedientes de violaciones a derechos humanos durante el conflicto, cuyo máximo esfuerzo estuvo en el juicio por genocidio contra el exdictador Efraín Ríos Montt; y la actual Thelma Aldana, quien procesa el juicio que llevó a la caída del expresidente Otto Pérez Molina durante su final de gestión y la expresidenta Roxana Baldetti. Ambas galardonadas y reconocidas por su valentía. Indudablemente se cuentan mucho más los casos que ambas impulsaron, pero estos son los más destacados.

Pero la contraparte que hace posible que estos procesos judiciales culminen corresponde a la labor de notables magistrados, cuya valentía y temple han permitido el avance de la justicia, entre ellos destaca la jueza Jazmín Barrios quien condenó a Ríos Montt (aunque las Cortes guatemaltecas anularon la condena una semana después); y el juez Miguel Ángel Gálvez. Si bien estos dos jueces han sido los más conocidos, es indudable que muchos otros magistrados están ya decantando por hacer justicia.

Uno de los elementos más relevantes en la coyuntura y que se relaciona directamente con estos procesos jurídicos, es lo que se inscribe en la lucha
La impunidad y la justicia transicional en la historia reciente de Guatemala: hacia un Estado democrático de derecho

María Patricia González Chávez 
contra la impunidad, y que da cuenta de un complejo y largo proceso por darle estructura y funcionalidad a un Estado democrático de derecho, donde el régimen político y su normativa actúen bajo los principios de la legalidad y de los derechos humanos, que cimienten un auténtico y estable Estado de derecho que empiece a darle legitimidad a un país cuya historia ha sido marcada por su ausencia.

\section{Análisis geopolítico global}

La Guatemala actual tiene una presencia activa de la comunidad internacional, que lleva a cabo una agenda específica y fuerte por apoyar la lucha contra la impunidad. Es pertinente mencionar que su estrategia ha sido ser visibles y contundentes en la necesidad de que el país avance en un desarrollo democrático que permita revertir aunque sea en el mediano plazo la terrible inequidad y sus bajos índices de desarrollo en todos los niveles.

Esta denominada comunidad internacional podemos identificarla en tres tipos de actores: los EE.UU., el sistema de Naciones Unidas, y la cooperación internacional; de ellos, hay una diferenciación importante, mientras que el sistema de las Naciones Unidas y la cooperación internacional se han identificado con impulsar una agenda democrática y de derechos humanos durante casi toda la historia reciente del país, en la política de los EE.UU. podemos empezar a hablar de una cierta transición.

Es importante mencionar que Guatemala en su relación con el mundo en la segunda mitad del siglo veinte mantuvo su tradicional dependencia con el citado país del norte, quienes lideraban intervenciones bajo la óptica e impulso de la Doctrina de Seguridad Nacional. Particularmente para los países de Centroamérica esta sumisión significaba adherirse a los planes diplomáticos, políticos y militares estadounidenses, que demandaban una lucha intensa y sin medida contra cualquier influencia o penetración de intereses externos al área hegemónica de los EE.UU.

Su concreción fue desde la permisibilidad manifiesta con la intervención directa en 1954 para truncar un breve periodo en la historia democrática de Guatemala, hasta la asesoría, acompañamiento y conducción de la basta estrategia contrainsurgente en los años del conflicto armado interno que provocó innumerables violaciones a los derechos humanos. Lo anterior tiene absoluta relevancia a la luz de los recientes acontecimientos en Guatemala, con el notorio protagonismo estadounidense en la lucha contra la impunidad en el país y el apoyo a todos los procesos de justicia transicional: lucha por la memoria, la justicia, la reparación y las garantías de no repetición.

Es decir, que presenciamos en un proceso de mediana duración, una transición en la forma de adecuar su agenda de intereses geopolíticos hacia la región, que van desde el apoyo a los regímenes autoritarios y militares de Guatemala, en el pasado, hasta una activa política de preocupación y acción en la 
lucha por un marco de principios democráticos y de derechos humanos que implica confrontar la impunidad, en el presente.

Los momentos que actualmente se viven en el país son dramáticos, ya que la acción continuada, profunda, extensiva e invasiva de los sistemas paralelos/ocultos/ilegales de poder, en los débiles marcos institucionales de gobierno, han potenciado de forma irrefrenable la vulnerabilidad de la población en todos los ámbitos de la vida, y en el marco de la crónica inequidad del país, se ha generado una grave crisis social con violencias de toda índole en el marco de un Estado capturado por la impunidad, que lo hace poco rentable para invertir ante el histórico y precario desarrollo económico del país.

Particularmente lo referente a la declaración oficial de los EE.UU. que formulada en las palabras del periodista José Rubén Zamora, es que Guatemala a la cabeza del llamado "Triángulo del Norte" (junto con El Salvador y Honduras) es una amenaza a su seguridad nacional, junto con Afganistán, Irán, Estado Islámico, guerra Ucrania-Rusia. Esto porque "En el Siglo XXI Guatemala es considerada una amenaza letal porque el producto no deseado de tres décadas de democracia es un narco-Estado. Casi la totalidad de la heroína, la cocaína, los precursores químicos que llegan a EE.UU., salen de Venezuela, Perú y Ecuador, y tienen como última bodega, por dos semanas, Guatemala" (Zamora 2016). ${ }^{5}$

Las interrogantes de esta transición deberán ser formuladas y contestadas a la luz de nuevos acontecimientos, que tienen estrecha relación con el impulso a la lucha de la corrupción en el mundo en el cual los EE.UU. juegan un papel importante, en tanto es un fenómeno que ya amenaza la estabilidad y reproducción del sistema económico global.

En esa línea de análisis, podemos identificar que ese cambio norteamericano hace un efecto positivo de confluencia en la lucha por un Estado democrático, a los esfuerzos tradicionalmente impulsados desde las agendas internacionales representadas en Guatemala por las agencias del sistema de Naciones Unidas y la cooperación internacional.

En el tiempo presente se puede constatar lo anterior con significativas presencias mediáticas en los casos de alto impacto contra la impunidad. En cuanto a los EE.UU., ha habido en la etapa reciente la visita de altos funcionarios a Guatemala, destacando en forma significativa la presencia del vicepresidente John Biden en la toma de posesión del nuevo presidente Jimmy Morales y la gran cobertura mediática que día a día está presente respecto al papel del país en la política local, al punto de interesantes polémicas respecto al asunto de la soberanía. ${ }^{6}$

5 En esta temática es relevante el artículo que difunde la BBC el 3 de septiembre del 2015 con el título: "El papel clave de Estados Unidos en la crisis de Guatemala".

6 De implicaciones aún no conocidas por lo reciente, es relevante la difusión y aclaraciones posteriores de la cancillería guatemalteca respecto de un comunicado oficial del Ministerio de Relaciones Exteriores fechado el 10 de marzo del 2016, dirigido al cuerpo diplomático en que se señala que si bien ha existido el respaldo de la cooperación internacional, indica textualmente: "Sin embargo, ello de ninguna manera autoriza que los agentes
La impunidad y la justicia transicional en la historia reciente de Guatemala: hacia un Estado democrático de derecho

María Patricia González Chávez 
El sistema de Naciones Unidas por su parte, ha mantenido amplia y permanente presencia en todos los asuntos de la defensa y promoción de los derechos humanos; todas las agencias han tenido manifiesta incidencia en cada uno de sus ámbitos temáticos y sectoriales, pero destacan particularmente la Oficina del Alto Comisionado, con Alberto Brunori; y especialmente la coordinadora residente de las Naciones Unidas y representante del PNUD, Valerie Julliand. Específicamente para el apoyo al sector justicia, como elemento clave para apoyar en la instauración de un Estado democrático de derecho, la colaboración del sistema de Naciones Unidas se materializó en la CICIG.

Por su parte, la cooperación ha estado presente a través de fondos y acciones concretas de apoyo a todo el proceso de lucha con la impunidad. Entre las acciones más recientes está la donación de 1,5 millones de euros que Alemania hizo a la CICIG, en cuyo evento público, su Comisionado Iván Velázquez, declaró que este apoyo era muy importante para continuar con el compromiso de lucha contra la impunidad en 2016, que además contribuye a fortalecer al Ministerio Público. Para el efecto se firmó una declaración conjunta de intenciones por el embajador de Alemania, Matthias Sonn y Valerie Julliand por el sistema de Naciones Unidas. El reconocimiento al apoyo de la cooperación internacional quedó patente en las palabras de Julliand: "No podríamos hacer este trabajo sin el apoyo de los países donantes, esto es absolutamente determinante" (Embajada Alemana 2015).

Analizando de conjunto los registros anteriores, podemos afirmar que la comunidad internacional en su conjunto ha tenido un especial y sólido apoyo a los procesos de justicia contra la impunidad, con especial énfasis en el presente. En este sentido es memorable la significativa foto que registró una declaración conjunta donde aparecen embajadores acreditados en Guatemala de Suecia, los EE.UU., España y Canadá; Julliand y Brunori por el sistema de Naciones Unidas; actores locales de la sociedad civil agrupados en el Foro Guatemala; y la Fiscal General, Thelma Aldana, el 1 de agosto del 2015. ${ }^{7}$ En el reporte periodístico se señala que las declaraciones se dirigieron a resaltar con alto grado de aprobación, la valiente labor de la señora Aldana.

\footnotetext{
diplomáticos de algunos países y organismos internacionales indebidamente se arroguen el derecho de intervenir en los asuntos internos del país, lo que incluye abstenerse de discutir y emitir opiniones de censura al gobierno y otros actores de la vida nacional, en los medios de comunicación", (Ávila 2016).

7 Para más información: http://elperiodico.com.gt/2015/08/01/pais/comunidad-internacional-y-foro-guatemala-respaldan-labor-del-ministerio-publico-y-la-cicig/
} 


\section{CREOMPAZ y el caso "Molina Theissen"}

El caso CREOMPAZ

A solicitud de la Unidad de Casos Especiales del Conflicto Armado Interno (UCECAI) y de la Fiscalía de Sección de Derechos Humanos del Ministerio Público (MP), la fundación de Antropología Forense de Guatemala-FAFG inició el 27 de febrero del 2012 la exhumación de fosas comunes en las instalaciones que actualmente ocupa CREOMPAZ. Desde esta fecha al 18 de abril de 2013 se han localizado 533 osamentas en 84 fosas excavadas (IW 2013).

Corresponden al periodo más cruento del conflicto entre 1981 y 1982, y la mayoría a hombres jóvenes. Muchos cuerpos presentaban las manos atadas y los ojos vendados, que son indicio de ejecuciones sumarias. De acuerdo a lo presentado por el Ministerio MP los cuerpos y objetos encontrados corresponden a casos de desaparición forzada y delitos de lesa humanidad contra hombres, mujeres y niños no combatientes.

La prueba clave que permitió determinar el avance del proceso judicial y dar principio de certeza a los testimonios previos, corresponde a la identificación del ADN de un familiar sobreviviente con una mujer encontrada en una de las fosas clandestinas junto con otras 63 personas, mujeres y niños en su mayoría, secuestradas por el ejército en 1982 en Río Negro, Alta Verapaz.

La coincidencia del ADN de los familiares de Martina Rojas con el ADN recuperado en la osamenta, comprueba el testimonio de los sobrevivientes, explica Fredy Peccerelli. 'Esto es muy importante ante los ojos de los propios familiares: demostrarle al mundo que ellos no son mentirosos. Durante 30 años, han sido acusados de inventar todo lo que pasó, de ser guerrilleros, de ser cualquier cosa. Y ahora, siquiera por medio de una persona, pueden mostrar que lo que llevan 30 años diciendo es cierto', afirma el director de FAFG (Escalón 2013).

De acuerdo a la información que empieza a fluir a partir de la captura de los militares, se explica que el proceso de investigación ha sido complejo y ha llevado muchos años. Así, es como el 7 de enero los medios de comunicación amanecen con abundante información que daría un giro importante en la Justicia transicional en Guatemala, la cobertura minuciosa que detallaba la información sobre la captura y señalamiento el día anterior de los militares implicados en el caso CREOMPAZ y "Molina Theissen”. Las notas periodísticas informaban que la Fiscal General en conferencia de prensa anunciaba la captura de 14 militares retirados señalados como responsables de la desaparición forzada y delitos contra deberes de la humanidad contra las 558 víctimas inhumadas en la base militar de Cobán.

De acuerdo a la cobertura periodística del proceso jurídico de CREOMPAZ, el 19 de enero se da a conocer que 11 de los 14 militares detenidos son ligados
La impunidad y la justicia transicional en la historia reciente de Guatemala: hacia un Estado democrático de derecho

María Patricia González Chávez 
a proceso. Los tres militares restantes no son procesados debido a que la jueza Claudette Domínguez consideró sus casos como "falta de mérito" por incongruencias en las fechas que presentó el MP y deberán guardar prisión domiciliaria. La jueza otorgó tres meses para que la Fiscalía complete la investigación, y posteriormente decidir si debe iniciar o no el juicio oral y público (EFE 2016).

Los 11 militares retirados ligados a proceso son: General Manuel Benedicto Lucas García, José Antonio Vásquez García, Carlos Augusto Garavito Morán, Raúl Dehesa Oliva, Gustavo Alonzo Rosales García, César Augusto Cabrera Mejía, Ismael Segura Abularach, Juan Ovalle Salazar, Byron Humberto Barrientos Díaz, César Augusto Ruiz Morales y Luis Alberto Paredes Nájera. Los 3 militares que no fueron procesados y que deben permanecer bajo arresto domiciliario son: Pablo Roberto Saucedo Mérida, Carlos Humberto Rodríguez López y Edgar Rolando Hernández. En el recuadro "La Zona Militar 21 y el caso Molina Theissen” se detalla esta información.

\section{“La Zona Militar 21 y el caso Molina Theissen”}

Un asunto que queda pendiente respecto a CREOMPAZ es la cuestión de la responsabilidad de las NNUU en el tema y la recomendación de Impunity Watch es que deben tomarse resoluciones lo más rápido posible, en tanto las instalaciones que tienen el resguardo del Sistema de Naciones Unidas se convirtió en una gigantesca escena del crimen del pasado: "El Departamento de Operaciones de Mantenimiento de la Paz de la ONU (DPKO, por sus siglas en inglés) a través de su Servicio de Capacitación Integral (ITS) debe retirar o suspender indefinidamente la certificación a CREOMPAZ como Unidad Académica. Dicha certificación contribuye a legitimar el papel del Ejército de Guatemala durante el Conflicto Armado Interno" (IW 2013: 8).

\section{El caso "Molina Theissen"}

Junto con la noticia de la captura de los militares por el caso CREOMPAZ se difunde también la captura de militares por la desaparición forzada del menor de 14 años Marco Antonio Molina Theissen, el 6 de octubre de 1981, como un caso emblemático de crueldad extrema.

Los testimonios refieren que el menor fue raptado por soldados vestidos de civil delante de su madre Emma Theissen en casa de la familia, en represalia porque su hermana Emma Molina Theissen se había logrado escapar de una base militar adonde había sido llevada tras ser capturada un mes antes en un retén militar y ser victimad de tortura y violaciones. Los sindicados por este caso son: el coronel retirado, Francisco Luis Gordillo Martínez; el segundo comandante, Edilberto Letona Linares; el oficial S-2, Hugo Ramiro 
Zaldaña Rojas, y el general de división Manuel Antonio Callejas Callejas (Chumil 2016).

Aun con los testimonios y pruebas, los militares intentaron escabullir la justicia maniobrando judicialmente para que se les aplicara la amnistía de la Ley de Reconciliación Nacional. La Sala Primera de Apelaciones negó la petición, debido a que NO se aplica perdón para delitos de lesa humanidad.

\section{A manera de conclusión: la intemporalidad en la lucha contra la impunidad}

En cada esfuerzo de memoria o de justicia, Guatemala se acerca a enfrentar en su presente los hechos dramáticos del pasado desde una perspectiva diferente. En este avance significativo de los casos que permiten recuperar los hechos para dignificar a las víctimas y sobrevivientes, y castigar a los culpables, se avanza y rectifica cómo escribir nuevas narrativas históricas. Las lecturas se entrecruzan y más que contradecirse se acompañan en visibilizar la enorme distancia que existe entre los responsables de los crímenes y los otros. Habiéndose erigido una historia oficial no textualizada con claridad, aparecen entonces las voces acalladas por decenios.

Varios militares procesados en los casos CREOMPAZ y "Molina Theissen" han sido nombres conocidos ámbito de la justicia transicional en Guatemala, como parte de los procesos que víctimas y sobrevivientes han encausado en la lucha por la memoria, la justicia y la reparación, por su responsabilidad de violaciones a los derechos humanos en el conflicto armado interno. En diversas fuentes se encuentran datos y pruebas testimoniales que dan cuenta de la participación de los inculpados en las masivas acciones represivas contrainsurgentes contra población no combatiente. Ahora toca el turno a la justicia que con el valor probatorio de lo encontrado en años de averiguaciones se logre hacer justicia.

Y más allá del recuento pendiente del pasado, ahora presenciamos una importante transición de la justicia transicional a la justicia, por explicarlo de alguna manera, al encontrar estrechas relaciones de las estrategias del pasado contrainsurgente ejecutadas por actores que en el presente tienen relevancia y están estrechamente vinculados con sectores de poder gobernante actual. Como es el caso de que muchos militares procesados en los casos revisados pertenecen a la ya mencionada asociación AVEMILGUA, que fundaron el partido FCN por el cual es presidente actual Jimmy Morales. Específicamente el militar que funda dicha asociación, Ovalle siendo diputado y sin prosperar su antejuicio es previsible que genere permanentemente pulsos que confronten las reformas estructurales pendientes que impulsen los procesos de democratización y el Estado de derecho.

Así la lucha contra la impunidad conlleva una perspectiva de largo aliento, lo que permite considerar que toda lucha del presente y del pasado se po-
La impunidad y la justicia transicional en la historia reciente de Guatemala: hacia un Estado democrático de derecho

María Patricia González Chávez 
tencializan mutuamente y dan pie para esperar mejores cosas del futuro, si se mantiene el ritmo y la dirección por este pulso de la lucha integral por la justicia.

El médico Carlos Martín Beristain, en su peritaje de la Sentencia ante la Corte Interamericana de Derechos Humanos por el caso "Molina Theissen" de julio del 2004, no deja lugar a dudas con estas ideas fundamentales en torno a la impunidad: los efectos educativos en tanto se da un cambio de valores en una sociedad donde se paraliza la capacidad de denunciar, o denunciar se convierte en una nueva fuente de peligro.

“Esto genera la llamada 'impotencia aprendida', es decir, se aprende que no se puede hacer nada para cambiar y que lo que hay que hacer es volver a las formas más primitivas de adaptación para protegerse. Otro efecto de la impunidad, dentro de ese cambio de valores, es que estimula el aumento de las venganzas privadas. Cuando no hay un sistema judicial que responda en un ámbito público a generar un cierto reequilibrio después de ocurrida una violación o hecho traumático, se produce un aumento de la violencia social. Asimismo, la impunidad supone un riesgo de repetición de atrocidades ocurridas en el pasado, en el sentido de que los responsables siguen teniendo control del proceso político posterior y cualquier intento que se hace para generar un nuevo sistema de justicia está controlado“(CIDH 2004).

Finalmente, expone la gran advertencia de que un contexto de impunidad lleva muchas veces al descrédito de la democracia, porque el valor de la justicia no es rescatado como el valor de un nuevo proceso social, y ello induce a generar situaciones en las cuales las violaciones de derechos humanos se consideran parte de la salida para luchar contra un contexto de impunidad. Por último, la justicia tiene el valor de confirmar que determinados hechos se han producido, es decir, cuando no hay justicia la verdad se "hiere" fácilmente.

A manera de análisis final puede concluirse que todo este proceso de la justicia se inscribe en la historia reciente desde una perspectiva de mediana duración, con una explicación que tiene que ver con que los Acuerdos de Paz no pudieron garantizar la desmovilización efectiva de estructuras operativas inicialmente montadas con funciones contrainsurgentes, que terminaron finalmente funcionando para operaciones con fines más vinculados a la criminalidad organizada. Y, por otro lado, el proceso de paz tampoco generó un diseño sistemático e integral de justicia transicional, pues se amnistió únicamente a los delitos comunes y conexos, y dejó en manos de "los agraviados" y el sistema de justicia, el juzgamiento de delitos de lesa humanidad, si es que los primeros lograban encaminar querellas al respecto.

Desde esta perspectiva, es posible brindarle un alto valor al esfuerzo por avanzar hacia un Estado democrático de derecho, en el sentido de fortalecer procesos que reúnen la búsqueda de la justicia, desde las mismas estructuras jurídicas del Estado, desde los principios democráticos y de los derechos humanos. 


\section{Bibliografía}

ACAN-EFE (2016), Baltasar Garzón: impunidad se debe a protección de elite minoritaria, "La Noticia", 31.03.2016, disponible en: http://lanoticiaenguatemala.com/category/crisisen-guatemala/, fecha de consulta: 04.04.2016.

Aguirre C. (1996), Braudel y las ciencias humanas, Montesinos, Biblioteca de Divulgación Temática 66, Barcelona.

Aguirre C. (1999), La Escuela de los Annales. Ayer, Hoy, Mañana, Montesinos, Biblioteca de Divulgación Temática 69, Barcelona.

Ávila A. (2016), La Cancillería le envía una nota a diplomáticos y les pide 'no intervenir', "Publinews", 17.03.2016, disponible en: http://www.publinews.gt/nacionales/la-cancilleriale-envia-una-nota-a-diplomaticos-y-les-pide-no-intervenir/Tetpcr---vC7nywTisb7s/, fecha de consulta: 25.03.2016.

Bermúdez A. (2015), El papel clave de Estados Unidos en la crisis de Guatemala, "BBC Mundo", 03.09.2015, disponible en: http://www.bbc.com/mundo/noticias/2015/09/150831_ guatemala_estados_unidos_corrupcion_cicig_ab\#share-tools, fecha de consulta: 25.03.2016.

Boche E. (2016), Benedicto Lucas, entre los señalados por atrocidades en la base de Cobán, "El Periódico Guatemala", 07.01.2016, disponible en: http://elperiodico.com.gt/2016/01/07/ pais/cae-el-capo-de-capos/, fecha de consulta: 04.04.2016.

Calveiro P. (2005), Política y / o Violencia. Una aproximación a las guerrillas de los años 70, Grupo Editorial Norma, Buenos Aires.

CEH, Comisión para el Esclarecimiento Histórico (1999), Guatemala, Memoria del Silencio, Informe de la Comisión para el Esclarecimiento Histórico, Oficina de Servicios para Proyectos de las Naciones Unidas (UNOPS), Guatemala.

Chumil K. (2016), Secuestran documentos en el Mindef por Caso Molina Theissen, "Diario La Hora", 18.03.2016, disponible en: http://lahora.gt/secuestran-documentos-en-el-mindefpor-caso-molina-theissen/, fecha de consulta: 04.04.2016.

CIDH, Corte Interamericana de Derechos Humanos (2004), Caso Molina Theissen Vs. Guatemala. Sentencia de 03.07.2004. (Reparaciones y Costas), 03.06.2004, disponible en: www.corteidh.or.cr/docs/casos/articulos/seriec_108_esp.pdf, fecha de consulta: 04.04.2016.

Convergencia por los Derechos Humanos - Guatemala, Comunicado. El caso CREOMPAZ tiene vida jurídica porque se basa en el Estado de Derecho, "Equipo de Estudios Comunitarios y acción Psicosocial (ECAP)", 17.01.2016, disponible en: http://www.ecapguatemala. org.gt/comunicados/el-caso-creompaz-tiene-vida-jur\%C3\%ADdica, fecha de consulta: 04.04.2016.

De León Q. (2016), Militares detenidos por violaciones a derechos humanos durante la guerra, "Prensa Comunitaria" 06.01.2016, disponible en: https://comunitariapress.wordpress. com/2016/01/06/militares-detenidos-por-violaciones-a-derechos-humanos-durante-laguerra/, fecha de consulta: 04.04.2016.

EFE (2016), Procesan a 11 de los 14 militares detenidos por 558 desapariciones en Guatemala, "EFE Agencia", 19.01.2016, disponible en: http://www.efe.com/efe/america/ politica/procesan-a-11-de-los-14-militares-detenidos-por-558-desapariciones-enguatemala/20000035-2814397, fecha de consulta: 04.04.2016.

Embajada Alemana en Guatemala (2015), Alemania reitera su apoyo a la Comisión Internacional contra la Impunidad en Guatemala con 1,5 millones de euros, "Embajada de
La impunidad y la justicia transicional en la historia reciente de Guatemala: hacia un Estado democrático de derecho

María Patricia González Chávez 
Alemania en Guatemala", diciembre de 2015, disponible en: http://www.alemaniaparati.diplo. de/Vertretung/mexiko-dz/es/03-PoliticaExterior/Lazos/AlemaniaApoyaCICIGGuatemala. html, fecha de consulta: 20.03.2016.

Escalón S. (2013), Masacre Rio Negro-Los dos entierros y el funeral de Martina Rojas, "Plaza Pública", 01.10.2013, disponible en: https://www.plazapublica.com.gt/content/los-dosentierros-y-el-funeral-de-martina-rojas, fecha de consulta: 20.03.2016.

González M. P. (2008), Reforma del Sector Seguridad y Justicia Transicional en Guatemala, desde la Perspectiva Sistémica de los Derechos Humanos, Tesis de la Maestría en Derechos Humanos y Democracia. Facultad Latinoamericana de Ciencias Sociales (FLACSO) México, México.

González M. P. y De León C. R. (2012), Transitional Justice in Guatemala, en: Popovski V., Serrano M. (eds.), After Oppression: Transitional Justice in Latin America and Eastern Europe, United Nations University Press, Tokyo, pp. 196-221.

González M. P. y González P. B. (2011), La Urgencia de la Historia: Justicia Transicional, Género y Etnicidad en Guatemala, Programa de Naciones Unidas para el Desarrollo (PNUD), Instituto de la Mujer (IUMUSAC) e Instituto de Estudios Indígenas (IDEI) de la Universidad de San Carlos de Guatemala. Magna Terra, Guatemala.

IW, Impunity Watch (2013), Policy Brief: Las Exhumaciones en el Comando Regional de Entrenamiento de Operaciones de Mantenimiento de Paz (CREOMPAZ), IW, noviembre de 2013.

MINDEF-GUA, Ministerio de la Defensa Nacional-Guatemala, Comando Regional de Entrenamiento de Operaciones de Mantenimiento de Paz, Reseña Histórica, disponible en: http://www.mindef.mil.gt/onu/creompaz/historia.html, fecha de consulta: 02.04.2016.

Orozco A. (2016), MP solicitó antejuicio contra diputado electo del FCN, "Prensa Libre", 06.01.2016, disponible en: http://www.prensalibre.com/guatemala/justicia/edgar-ovallemaldonado-mp-solicito-antejuicio-contra-diputado-electo-de-fen, fecha de consulta: 01.04.2016.

Urizar A. (2015), Comunidad Internacional y Foro Guatemala respaldan labor del Ministerio Público y la CICIG, "El Periódico Guatemala", 01.08.2015, disponible en: http://elperiodico. com.gt/2015/08/01/pais/comunidad-internacional-y-foro-guatemala-respaldan-labor-delministerio-publico-y-la-cicig/, fecha de consulta: 20.03.2016.

Zamora J. R. (2016), Don Jimmy, al entendido por señas..., "El Periódico Guatemala", 07.01.2016, disponible en: http://elperiodico.com.gt/2016/01/07/opinion/don-jimmy-alentendido-por-senas/, fecha de consulta: 25.03.2016. 